\title{
NSAIDs Hypersensitivity: When and How to Desensitize?
}

\author{
Joanna Makowska, MD, $P h D^{1, *}$ \\ Marcin Makowski, MD, PhD ${ }^{2}$ \\ Marek L. Kowalski, MD, PhD ${ }^{3}$
}

\author{
Address \\ *,1Department of Rheumatology, Medical University of Lodz, Lodz, Poland \\ Email: joanna.makowska@umed.lodz.pl \\ ${ }^{2}$ Department of Interventional Cardiology and Cardiac Arrhythmias, Medical \\ University of Lodz, Lodz, Poland \\ ${ }^{3}$ Department of Immunology, Rheumatology and Allergy, Medical University of \\ Lodz, Lodz, Poland
}

Published online: 31 March 2015

(C) Springer International Publishing AG 2015

This article is part of the Topical Collection on Drug Allergy

Keywords Non-steroidal anti-inflammatory drugs · NSAID · Hypersensitivity · Aspirin desensitization

\section{Opinion statement}

Non-steroidal anti-inflammatory drugs (NSAIDs) are the most commonly used drugs and are among the major causes of hypersensitivity reactions. NSAIDs can evoke different types of both immunological and non-immunologically mediated hypersensitivity reactions, and management of these reactions depends on type of hypersensitivity reaction. As NSAIDs are comprised of several drugs with different chemical structures which can inhibit both cyclooxygenases or selectively cyclooxygenase type 2 (COX-2), in most of the cases, it is possible to find a safe non-cross-reactive drug for a patient. However, in certain situations, especially when patients require anti-platelet treatment, patients can be desensitized to aspirin.

\section{Introduction}

Non-steroidal anti-inflammatory drugs (NSAIDs) and aspirin are among the most commonly prescribed and used drugs in the world and, along with antibiotics, are the top two (depending on the population studied) causes of adverse drug reactions [1]. It is estimated that hypersensitivity to NSAIDs affects from 0.5 to $1.9 \%$ of general population [2], but in certain populations like patients with bronchial asthma or with chronic rhinosinusitis, the prevalence of NSAIDs hypersensitivity is much higher $[3,4 \bullet \bullet]$.
The management of drug hypersensitivity reactions always starts with advice on avoidance of the culprit drug and any cross-reactive compounds $[5 \bullet \bullet]$, but in some patients, induction of tolerance to the drug can be also considered. In case of NSAIDs hypersensitivity, despite large number of compounds belonging to this group, only desensitization to aspirin has been sufficiently documented. 


\section{When to desensitize a patient with NSAIDs hypersensitivity?}

While considering aspirin desensitization in a patient with a history of hypersensitivity to NSAIDs, the following aspects have to be taken into consideration:

1. Determination of a subtype of NSAIDs hypersensitivity, since desensitization is possible only for some subtypes, while in other subtypes desensitization may be contraindicated.

2. Analysis of clinical benefit from treatment with aspirin (NSAID) after desensitization.

3. General safety of desensitization procedure.

4. Selection of desensitization protocol-different protocols are used depending on the indication for desensitization.

\section{Subtypes of NSAIDs hypersensitivity and possibility of desensitization}

NSAIDs can evoke a wide spectrum of adverse drug reactions (respiratory, cutaneous, anaphylactic, or other organ-specific) involving different pathomechanisms. Induction of tolerance to aspirin is possible and indicated only in two subtypes of NSAIDs hypersensitivity: (1) NSAIDs-exacerbated respiratory disease (NERD) and (2) NSAIDs-induced urticaria/angioedema (NIUA), thus determination of the type of hypersensitivity is prerequisite to successful desensitization.

According to novel classification of NSAIDs hypersensitivity, either immunologically and non-immunologically mediated reactions can be distinguished $[4 \bullet \bullet]$ (Table 1 ). Most of the hypersensitivity reactions to NSAIDs are nonimmunologically mediated but are cross-reactive hypersensitivity reactions as the patients usually do not tolerate all NSAIDs with COX-1 inhibitory activity.

Among these cross-reactive reactions, three clinical subtypes can be distinguished:

\section{NSAIDs-exacerbated respiratory disease (NERD)}

This hypersensitivity reaction is manifested mainly by respiratory symptoms and occurs in patients with underlying chronic airway disease like asthma and/or rhinosinusitis with nasal polyps. NSAIDs-induced bronchial symptoms (dyspnea, cough) usually appear within 1-2 $\mathrm{h}$ and are preceded by nasal symptoms

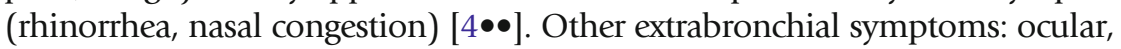
cutaneous (flushing of the upper thorax, urticaria, and/or angioedema) or gastric are less frequent [6]. Typical natural history of the diseases starts with development of chronic rhinosinusitis with polyps, followed by asthma, which usually precede the first of hypersensitivity reaction [3]. Patients with NERD usually have more severe asthma as compared to aspirin-tolerant asthmatics [7]. Furthermore, chronic rhinosinusitis in NERD patients is usually more severe, very often 
Table 1. Classification of NSAIDs hypersensitivity reactions

\begin{tabular}{|c|c|c|c|c|}
\hline & Reaction & Abb & Definition & Desensitization \\
\hline \multirow[t]{3}{*}{$\begin{array}{l}\text { Non- } \\
\text { immunologically } \\
\text { mediated reactions }\end{array}$} & $\begin{array}{l}\text { NSAIDs- } \\
\text { exacerbated } \\
\text { respiratory } \\
\text { disease }\end{array}$ & NERD & $\begin{array}{l}\text { Hypersensitivity reactions } \\
\text { induced by aspirin or other } \\
\text { NSAIDs manifesting primarily as } \\
\text { bronchial obstruction, dyspnea, } \\
\text { and nasal congestion/rhinorrhea, } \\
\text { occurring in patients with an } \\
\text { underlying chronic airway } \\
\text { respiratory disease (asthma/ } \\
\text { rhinosinusitis/nasal polyps). }\end{array}$ & $\begin{array}{l}\text { Possible, everyday } \\
\text { treatment } \\
\text { with aspirin have } \\
\text { additional } \\
\text { beneficial effect } \\
\text { on rhinosinusitis } \\
\text { and asthma course }\end{array}$ \\
\hline & $\begin{array}{l}\text { NSAIDs- } \\
\text { exacerbated } \\
\text { cutaneous } \\
\text { disease }\end{array}$ & NECD & $\begin{array}{l}\text { Hypersensitivity reactions } \\
\text { induced by aspirin or other NSAI } \\
\text { Ds manifesting as wheals and/or } \\
\text { angioedema occurring in patients } \\
\text { with a history of chronic } \\
\text { spontaneous urticaria. }\end{array}$ & $\begin{array}{l}\text { Generally not } \\
\text { recommended }\end{array}$ \\
\hline & $\begin{array}{l}\text { NSAIDs-induced } \\
\text { urticaria } \\
\text { angioedema }\end{array}$ & NIUA & $\begin{array}{l}\text { Hypersensitivity reactions } \\
\text { induced by aspirin or other NSAI } \\
\text { Ds manifesting as wheals and/or } \\
\text { angioedema occurring in } \\
\text { otherwise healthy subjects } \\
\text { (without history of chronic } \\
\text { spontaneous urticaria). } \\
\text { Symptoms are induced by at } \\
\text { least two NSAIDs with different } \\
\text { chemical structure (not } \\
\text { belonging to the same } \\
\text { chemical group). }\end{array}$ & Possible \\
\hline \multirow[t]{2}{*}{$\begin{array}{l}\text { Immunologically } \\
\text { mediated } \\
\text { reactions }\end{array}$} & $\begin{array}{l}\text { Single NSAID- } \\
\text { induced } \\
\text { urticaria/ } \\
\text { angioedema } \\
\text { or anaphylaxis }\end{array}$ & SNIUAA & $\begin{array}{l}\text { Immediate hypersensitivity } \\
\text { reactions to a single NSAID } \\
\text { or to several NSAIDs belonging } \\
\text { to the same chemical group, } \\
\text { manifesting as urticaria, } \\
\text { angioedema and/or anaphylaxis. } \\
\text { These subjects tolerate other } \\
\text { chemically non-related NSAIDs } \\
\text { and usually do not have a history } \\
\text { of chronic urticaria or asthma. }\end{array}$ & No data \\
\hline & $\begin{array}{l}\text { NSAIDs-induced } \\
\text { delayed } \\
\text { hypersensitivity } \\
\text { reactions }\end{array}$ & NIDHR & $\begin{array}{l}\text { Hypersensitivity reactions to a } \\
\text { single NSAID appearing usually } \\
\text { within } 24-48 \mathrm{~h} \text { after drug } \\
\text { administration and manifesting } \\
\text { by either skin symptoms } \\
\text { (exanthema, fixed drug } \\
\text { eruption), other organ-specific } \\
\text { symptoms (e.g., renal, } \\
\text { pulmonary), or severe cutaneous } \\
\text { adverse reactions (SCAR). }\end{array}$ & $\begin{array}{l}\text { No available } \\
\text { protocols, } \\
\text { desensitization } \\
\text { contraindicated in } \\
\text { SCAR, organ } \\
\text { involvement } \\
\text { (pneumonitis, } \\
\text { nephritis) }\end{array}$ \\
\hline
\end{tabular}


complicated by recurrent nasal polyp formation which responds less to surgical treatment [3]. NERD is one of non-immunological, cross-reactive types of hypersensitivity as patients hypersensitive to one NSAIDs react to aspirin and other NSAIDs which are COX-1 inhibitors, while weak COX-1 inhibitors or preferential COX-2 inhibitors are usually well tolerated [8-10].

Aspirin desensitization

Aspirin desensitization in this subtype of hypersensitivity can be easily achieved, and treatment with aspirin after desensitization may be beneficial for improving symptoms of the underlying chronic diseases, asthma, and rhinosinusitis with nasal polyps $[11 \bullet \bullet, 12]$.

\section{NSAIDs-exacerbated cutaneous disease (NECD)}

This type of hypersensitivity is observed in patients suffering from chronic spontaneous urticaria. Clinical symptoms (urticaria and angioedema) typically occur 0.5 to $6 \mathrm{~h}$ after ingestion of NSAIDs. NSAIDs-induced reactions are less frequent and less intense when chronic urticaria is in remission or under control. The mechanism of the reaction, similarly to NERD, is related to the inhibition of cyclooxygenase -1 by a culprit drug, resulting in increased generation of cysteinyl leukotrienes [13]. Thus, patients with NECD would have a cross-reaction with COX-1 inhibitors, while selective COX-2 inhibitors are generally well tolerated by the majority of them [14].

Aspirin desensitization

In this subtype of NSAIDs hypersensitivity, the tolerance of aspirin may be difficult to achieve and in some patients, cutaneous symptoms may be even exacerbated by the procedure [15]. Thus, aspirin desensitization in NECD patients is not recommended, even though there have been some reports of successful induction of tolerance to aspirin $[16,17]$.

\section{NSAIDs-induced urticaria/angioedema (NIUA)}

The clinical pattern of NSAID-induced symptoms is similar to NECD (wheals and/or angioedema); however, in contrast to NECD, patients with NIUA do not have history of chronic spontaneous urticaria. The mechanism is thought to be related to COX-1 inhibition, but it has not been well documented $[14,18 \bullet]$.

Aspirin desensitization

Aspirin desensitization is possible in most patients. Tolerance state can be

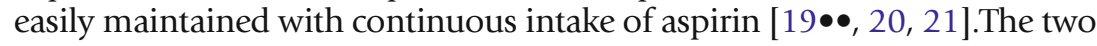
remaining subtypes of NSAIDs hypersensitivity are immunologically mediated and are distinguished by intolerance of a single drug (chemical molecule) and good tolerance of other chemically unrelated NSAIDs. 


\section{Single NSAIDs-induced urticaria/angioedema/anaphylaxis (SNIUAA)}

A subpopulation of patients reports immediate hypersensitivity reaction to a single NSAID (or to several NSAIDs but belonging to the same chemical group). Patients usually present with a history of good tolerance to other chemically unrelated NSAIDs, including aspirin [18•]. The symptoms range from mild urticaria and localized angioedema to laryngeal edema and anaphylaxis and usually develop within first hour after the drug intake [18•]. However, in some instances, symptoms may develop within minutes or even seconds (e.g., after intravenous injection of metamizole) [22]. These subjects are usually otherwise healthy individuals without any specific underlying chronic disease. The reactions are most often induced by pyrazolones, ibuprofen, or diclofenac; however, other NSAIDs as paracetamol have been implicated as well. Aspirin incidentally evokes hypersensitivity reactions in this mechanism.

There is no data on desensitization in this type of reactions. As symptoms of hypersensitivity are usually evoked by a single drug, the chemical compound with different chemical structure can be prescribed and will be well tolerated.

\section{NSAIDs-induced delayed hypersensitivity reactions (NIDHR)}

Reactions developing usually after more than $24 \mathrm{~h}$ after the drug intake are considered to represent delayed type of immunological hypersensitivity. Delayed cutaneous manifestation are the most common and involve maculopapular eruptions (MPE), fixed drug eruptions (FDE), photosensitivity reactions, delayed urticaria [23-25], and contact dermatitis [26]. In addition, severe drug hypersensitivity reactions (drug induced hypersensitivity syndrome (DIHS), acute generalized exanthematous pustulosis (AGEP), and severe cutaneous adverse reactions (SCAR) [27-29] as well as organ-specific injury (pneumonitis and nephritis) may occur [30].

The presumed immunological mechanism involves the stimulation of drugspecific CD4+ and CD8+ T cells through their T cell receptors (TCR) and represents a delayed type hypersensitivity (type IV according to Gell Coombs) T celldependent mechanisms have been documented in delayed urticaria, MPE induced by acedophenac [31] and metamizol and in SCAR induced by ibuprofen [32, 33].

Aspirin desensitization

There is no data on desensitization to aspirin. In most patients with delayed type hypersensitivity reactions (SCAR, DRESS, AGEP, and pneumonitis and

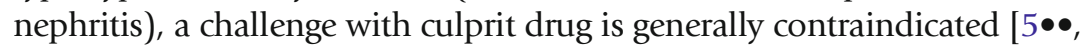
34]. In case of less severe delayed drug reactions, e.g., maculopapular eruptions, there is no attempts of desensitization have been reported. 
Furthermore, since the reactions are evoked by a single NSAID, the culprit drug can be usually replaced.

\section{Clinical indications to NSAIDs desensitization}

Avoidance of culprit drug as well as other cross-reactive compounds is the first recommendation in the management of NSAIDs hypersensitivity [4••]. If the treatment with analgesic/anti-inflammatory drug is needed, a non-cross-reactive drug should be given, selected depending on the known mechanism. Most patients with cross-reactive, non-immunologically mediated types of NSAIDs hypersensitivity will tolerate preferential COX-2 inhibitors like meloxicam or nimesulide or selective COX-2 inhibitors (celecoxib) with relevant anti-inflammatory effect. Aspirin, however, have additional important pharmacological effects going beyond anti-inflammatory or analgesic activity. As a key anti-platelet drug, aspirin is recommended for primary and secondary prevention in patients with a high risk of major cardiovascular events (death, myocardial infarction, or stroke) [35, 36]. Recent data show that low doses of aspirin can decrease the risk of certain malignant tumors development: e.g., colorectal cancer [37] or ovarian cancer [38].

Moreover, in patients with NSAIDs-exacerbated respiratory disease daily treatment with aspirin can bring additional beneficial effects like alleviation of nasal symptoms, decreased formation of nasal polyps, and reduced need for oral corticosteroids and sinus surgeries. Clinical indications for aspirin desensitization are listed in Table 2.

\section{Aspirin desensitization in patients with need for anti-platelet treatment}

Cardiovascular events are the major cause of mortality in developed countries

[39]. Aspirin is the most studied anti-platelet agent in this context of prevention

\section{Table 2. Clinical indications for aspirin desensitization}

1. Patients with need of anti-platelet treatment

2. Chemoprotection of certain types of cancer (colon cancer, ovarian cancer)

3. Patients with NERD and severe course of rhinosinusitis and asthma

4. Need for chronic anti-inflammatory treatment-patients with severe osteoarthritis, seronegative spondyloarthropathies
Treatment of acute coronary disease, stroke Secondary prevention of cardiovascular events (patients after acute coronary syndrome, stroke, patients after stent implantation, patients after coronary artery bypass surgery, patients with peripheral artery disease, patients with antiphospholipid syndrome

Primary prevention (patients with high risk of cardiovascular events, patients with antiphospholipid syndrome)

Colon cancer

Ovarian cancer

Severe osteoarthritis

Seronegative spondyloarthropathies 
and treatment of cardiovascular disease (coronary artery disease, stroke, peripheral artery disease). Aspirin decreases mortality and reinfarction when given as short-term therapy for acute myocardial infarction [40], when given to patients with unstable angina [41], and when given as long-term secondary preventive therapy in wide range of patients with cardiovascular disease [42].

Although, in recent years, novel anti-platelet drugs become available like adenosine diphosphate receptor inhibitors (clopidogrel, prasugrel, ticlopidine, ticagrelor), glycoprotein IIb/IIIa inhibitors (abciximab, eptifibatide), or adenosine reuptake inhibitors (dypirimidamole). Given its relative safety and low cost, aspirin will continue to be an important agent in the treatment and prevention of cardiovascular diseases.

Moreover, in certain clinical situations, dual anti-platelet therapy is mandatory, e.g., after myocardial infarction and/or after stent implantation [43, 44]. A great majority of patients after cardiovascular events will require treatment with aspirin till the end of life [43].

For patient with aspirin hypersensitivity and acute coronary syndrome, either use of clopidogrel or aspirin desensitization is recommended by cardiologists (ACC/AHA guidelines from 2007 [45] and ESC guidelines [46]).

Although there is plenty of data on safety of aspirin desensitization in patients with stable coronary heart disease, much more challenging is taking decision on aspirin desensitization in patient with acute coronary syndrome as patient very often received drugs that are contraindicated during desensitization (beta blockers and ACE inhibitors) and there is fear that hypersensitivity reaction which may occur can further destabilize the patient. Moreover, desensitization can be avoided by using more aggressive anti-platelet treatment with intravenous drugs such as abciximab, integrilin, or tirofiban.

There is limited data on aspirin desensitization in acute phase of acute coronary syndrome [47]. De Luca et al. presented in prospective way group of patient undergoing coronary angioplasty (53\% due to acute coronary syndrome) who were desensitized with aspirin. Procedure of intravenous desensitization was effective in $97.6 \%$ of patients [47]. Thus, it seems that at least some of the proposed protocols can be implemented safely even in patients with acute coronary syndrome. However, as the hypersensitivity reaction was not proven by challenge test, it is not clear how many of those patients were really hypersensitive. The aspirin desensitization in patients with ACS should be performed after stabilization of acute phase, and it should be performed in monitored conditions and by experienced staff.

An interesting approach to ASA-desensitization in patients with coronary artery disease has been proposed by Cortellini et al. A patient with stable coronary artery disease and history of mild symptoms after NSAIDs intake at first should be challenged with aspirin to confirm hypersensitivity [19]. If a patient presented history of severe symptoms after NSAID intake, desensitization procedure was done without attempts to confirm hypersensitivity. Interestingly, 29 from 30 patients with history of mild symptoms of urticaria and/or angioedema fully tolerated the cumulative dose of $160 \mathrm{mg}$ of acetylsalicylic acid during the challenge. There are at least 2 explanation of this observation, either patients were not hypersensitive or the threshold dose of aspirin to evoke clinical symptoms was not reached during the tolerance test. 


\section{Aspirin desensitization and aspirin treatment in patients with NERD}

It has been documented that in a subgroup of patients with NSAIDsexacerbated respiratory disease (NERD), ingestion of aspirin after desensitization results in alleviation of both upper and lower airway

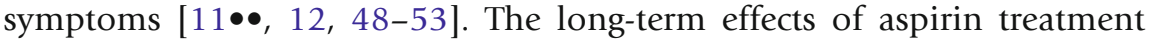
include improvement in nasal symptoms, decrease in the maintenance dose of intranasal glucocorticosteroids, and a decrease in the number of polypectomies [12, 50, 52, 54]. Aspirin desensitization can slow down regrowth of nasal polyps and prevent further nasal surgeries [55]. Usually, it is recommended that aspirin desensitization should follow sinus surgery [55].

Aspirin treatment after desensitization may also have an impact on asthma control. When the patients were treated with aspirin for 6 months to 6 years, a significant reduction in hospitalization, emergency room visits, outpatient visits was observed and in some patients, a reduction in daily oral prednisone doses was achieved $[12,49,50]$

There are two placebo-controlled studies that support these benefits.

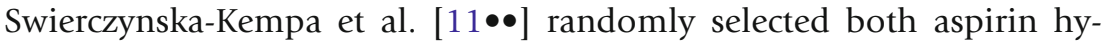
persensitive and aspirin-tolerant asthmatics to aspirin or placebo treatment group. The improvement in nasal symptoms score and reduction in sneezing and nasal blockade was observed only in patients with aspirin hypersensitivity treated with aspirin. The nasal symptoms improved within the first month of treatment, and improvement was seen throughout the entire observation period. However, it has to be noted that computed tomography (CT) sinus scan scores did not change in parallel to clinical improvement. Asthma control was improved, and the dose of inhaled corticosteroids was decreased; however, asthma symptoms score and spirometric values did not change significantly $[11 \bullet \bullet]$.

Efficacy of treatment with various doses of aspirin from 100 to $1300 \mathrm{mg}$ have been reported. While some studies report that aspirin dose as low as $100 \mathrm{mg}$ daily for 1-3 years may provide benefit with respect to the recurrence rate of nasal polyps, severity of bronchial asthma and sense of smell in desensitized patients with NERD [51], another studies suggest that clinical efficacy starts from $300 \mathrm{mg} /$ day [52]. However, it seems that the dose should be tailored to the patient and both clinical efficacy and side effects should be taken into consideration while determining the maintenance dose. A study comparing 325 with $650 \mathrm{mg}$ twice a day showed that in almost half of patients, half of the dose was enough while the rest of the patients required higher doses [56]. The reports from Scripps Clinic suggest starting with $650 \mathrm{mg}$ twice a day and titrate the dose down by $325 \mathrm{mg}$ each month, as tolerated [57]. In our clinic, we desensitize patient to $650 \mathrm{mg}$ of aspirin and give a maintenance dose of $325 \mathrm{mg}$ twice a day.

In order to maintain tolerance state, aspirin has to be given on a regular basis-if not, the tolerance state disappears after 2-5 days. In most of the studies, aspirin was given once or twice a day. 


\section{How and where to desensitize?}

Aspirin desensitization is a high-risk procedure, which has to be done after assessment of risk-benefit ratio following discussion with a patient. Before desensitization, the patient should be provided with information about procedure risk and benefits and sign the consent.

Desensitization is contraindicated in patients with previous severe, lifethreatening cutaneous reactions like Stevens-Johnson syndrome/toxic epidermal necrolysis, DIHS/DRESS, AGEP, erythema multiforme and serum sickness disease, and organ involvement $[5 \bullet \bullet, 34]$. Risk factors for severe bronchial reaction in patients with NERD during desensitization include severe reaction with fall of FEV1 $>20 \%$, uncontrolled asthma, baseline FEV1 less than $80 \%$, lack of leukotriene modifier premedication, previous emergency department visits due to asthma exacerbation [58].

\section{Where}

Desensitization procedure can be performed both in hospital and outpatient setting after risk stratification. The severity and time course of initial hypersensitivity reaction have to be assessed, and the concomitant use of medication such as beta blockers and ACE inhibitors and the severity of underlying disease need to be taken into consideration [59].

Patients with severe asthma, acute coronary syndrome, patients using beta blockers, angiotensin converting enzyme (ACE) inhibitors, severe lifethreatening aspirin hypersensitivity reaction, underlying medical condition that make management of hypersensitivity reaction more difficult (e.g., cardiac insufficiency) should be exceptionally desensitized (after careful assessment of risk-benefit ration), only in hospital settings.

If aspirin desensitization is to be performed in the outpatient setting, the following conditions should be fulfilled [59]:

- A physician experienced in assessing and treating acute, severe hypersensitivity reactions is immediately available for patient evaluation and treatment.

- Medically qualified personnel experienced with assessing and treating of severe asthma exacerbation is available to monitor patient.

- At least one experience medical staff member is solely dedicated to evaluation of patient being desensitized until desensitization is completed.

- The equipment for continuous respiratory and cardiovascular monitoring, spirometry, cardiopulmonary resuscitation, pulsoximetry, is readily available.

In summary, desensitization procedure should be performed by well-trained, experienced allergists and nurses who are familiar with treatment of acute hypersensitivity reactions and anaphylaxis. Emergency equipment for continuous pulmonary and cardiovascular monitoring and treatment like epinephrine, 
oxygen, beta- 2 mimetics, intravenous glucocorticosteroids, antihistamines, glucagon should be available at bedside.

\section{Preparation to desensitization and pretreatment}

Patient planned for desensitization should have stable underlying disease, e.g., asthma. Treatment of chronic diseases should be continued, but drug which can interfere treatment of hypersensitivity reaction like beta blockers or ACE inhibitors should be discontinued/replaced by drugs from other pharmacological groups whenever possible. The Macy's recommendation is to stop antihistamines $48 \mathrm{~h}$ before desensitization not to mask naso-ocular symptoms which usually precedes onset of bronchial symptoms and decreasing of FEV1. The use of asthma controller medication prior to desensitization is recommended as they prevent severe decreases of FEV1 [60]. Duration of the supervision depends on initial hypersensitivity reaction.

Pretreatment with leukotriene blockers may alleviate symptoms of breakthrough reaction in patients with NERD by shifting reaction from bronchial to naso-ocular symptoms [60].

\section{Desensitization procedures}

In most protocols for aspirin desensitization, the procedure begins with provoking the reaction with a standard, as low as possible aspirin dose (threshold dose) followed by administration of increasing doses which usually are well tolerated. However, it has been documented that the tolerance state to full dose of aspirin (e.g., $600 \mathrm{mg}$ ) can be also induced, without evoking the initial reaction, by timely and gradual administration of small, subthreshold doses of aspirin [61]. Such procedure has been recently referred to as "silent desensitization" [62].

There are two major types of protocol used in clinical practice for aspirin desensitization depending on the indications for the procedure: "slow desensitization" protocols used to desensitize patients with NSAIDs-exacerbated respiratory disease and "rapid desensitization" protocols used to desensitize patients with cardiologic indications to use low doses of aspirin (Table 3)

\section{Protocols for patients with NERD}

Several protocols for desensitization of patients with NERD have been proposed and used [58, 59, 63-67]. The recommended starting dose is between 10 and $30 \mathrm{mg}[58,59,63,65]$, but the time interval between consecutive increasing doses varies from $30 \mathrm{~min}$ to $24 \mathrm{~h}$ in different protocols [68]. The most widely used protocols have been proposed by the Scripps Clinic [63]. One of the proposed schedules advices giving following doses of aspirin: 30, 45, 60, 100, 150,325 , and $650 \mathrm{mg}$. The recommended time interval between doses is $3 \mathrm{~h}$, but FEV1 and clinical assessment should be performed every hour or upon presentation of any symptoms. Reaction will likely occur with doses between 20 and $101 \mathrm{mg}$, and reaction should be treated immediately. 
Table 3. Protocols (studies reporting rapid desensitization in patients with coronary heart disease) for aspirin desensitization

\begin{tabular}{|c|c|c|c|c|c|}
\hline Author & $\begin{array}{l}\text { No of patients } \\
\text { desensitized }\end{array}$ & $\begin{array}{l}\text { No of } \\
\text { protocol } \\
\text { steps }\end{array}$ & $\begin{array}{l}\text { Time } \\
\text { interval } \\
\text { between } \\
\text { subsequent } \\
\text { doses }\end{array}$ & $\begin{array}{l}\text { Success } \\
\text { rate }\end{array}$ & Journal \\
\hline Wong TJ & 11 & 10 steps & $10-30 \mathrm{~min}$ & $81 \%$ & JACI 2000;105:997-1001 \\
\hline Silberman S & 16 & $\begin{array}{l}8 \text { steps } \\
5 \text { steps }\end{array}$ & & $88 \%$ & Am J Cardiol 2005;95:509-510 \\
\hline Ortega-Loayza AG & 3 & 10 steps & $10-30 \mathrm{~min}$ & & Am J Sci 2010, 340 (5):418-20 \\
\hline Rossini R & 26 & 6 steps & $30 \min$ & $88.50 \%$ & Am J Cardiol 2008;101:786-89 \\
\hline Dalmau G & 5 & 8 steps & $15-20 \min$ & $100 \%$ & Rev Esp Cardiol 2009;62:224-30 \\
\hline Alijotas-Reig J & 4 & 9 (10) steps & $15 \min$ & $100 \%$ & $\begin{array}{l}\text { Am J Reprod Immunol } \\
2006 ; 55: 45-50\end{array}$ \\
\hline DeLuca G* & 43 & 9 steps & $30 \mathrm{~min}$ & $97.60 \%$ & Int J Cardiol 2013:167:561-63 \\
\hline Fajt ML & 9 & $10-12$ steps & & $89 \%$ & Crit Path Cardiol 2011, 10:17-21 \\
\hline McMullan KL & 26 & 7 steps & $15-20 \mathrm{~min}$ & $87.00 \%$ & Clin Cardiol 2013, 36:1, 25-30 \\
\hline Cortellini G & 35 & 12 steps & $20 \mathrm{~min}$ & $90 \%$ & $\begin{array}{l}\text { Eur Ann Allergy Clin Immunol } \\
\text { 2012; 44:160-162 }\end{array}$ \\
\hline
\end{tabular}

Following the dose that evoked symptoms (called the provoking/threshold dose) and before the next dose of aspirin is given, the patient should completely stabilize, and the respiratory function should return to baseline values. The provoking/threshold dose is usually repeated on the same day, although some recommend the next morning. If the dose is tolerated, the dose is increased every $3 \mathrm{~h}(101.25,162,325$, and $650 \mathrm{mg})$. The chance of a reaction to the repeated threshold dose is small, but if it occurs, the dose should be repeated again until reactions cease and then the next highest dose of aspirin may be given.

\section{Safety of long-term treatment with NSAIDs}

The incidence of side effects of aspirin treatment in patients with NERD followed by aspirin desensitization varies from $6-32 \%$. The most common adverse reactions in patients on maintenance therapy are the following:

1) Dyspepsia

2) Bleeding from gastrointestinal system

3) Urticaria/angioedema

4) Loss of tolerance and asthma/rhinosinusitis exacerbation

The concomitant use of proton pump inhibitors can prevent symptoms of dyspepsia, gastric ulceration, and bleeding, but it won't prevent bleeding from lower parts of gastrointestinal system. Recently published data indicates that proton pump inhibitors (PPIs) can even exacerbate NSAID-induced intestinal 
damage at least in part because of significant shifts in enteric microbial populations [69, 70]. Helicobacter pylori, an independent risk factor for ulcers, should be sought out and eradicated in patients at increased gastrointestinal risk, typically those with an ulcer history prior to aspirin desensitization [71].

\section{Protocols for patients with need of anti-platelet treatment}

Desensitization protocols for patients who need treatment with anti-platelet doses of aspirin differs from protocols used in NERD desensitization because: (a) patients need to be desensitized to lower dose of aspirin-75-150 mg, (b) patients represent different subtypes of hypersensitivity (NERD or NIUA), (c) very often, patients require rapid desensitization (patient with acute coronary syndrome).

Several protocols of rapid aspirin desensitization have been published $[19 \bullet \bullet, 20,21,47,72-77]$. These protocols differ in starting dose, time interval between subsequent doses, and number of steps. Rapid protocols usually start with lower aspirin dose (from 0.1 to $5 \mathrm{mg}$ of ASA) [20, 21, 72, 73], and increasing doses of aspirin are given every 10-30 min. Protocols consist of 5-12 steps. (Table 3)

Interesting, alternative approach to aspirin desensitization was proposed by DeLuca et al. [47] who employed intravenous protocol in patients with myocardial infarction. The desensitization procedure involved intravenous administration of nine sequential doses of aspirin $(1,2,4,8,16,32,64,128,250 \mathrm{mg})$

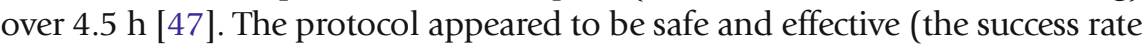
reached $97.6 \%$ ).

There is still lack of consensus, which protocol should be used for desensitization of cardiac patients, and what are the indication and contraindications to desensitization procedure. Although various authors report on excellent safety and efficacy of desensitization procedure (from 81-97 \% success rate), the real effectiveness of desensitization is not clear. The assessment of reported effects is difficult since most studies included patients with various, not well

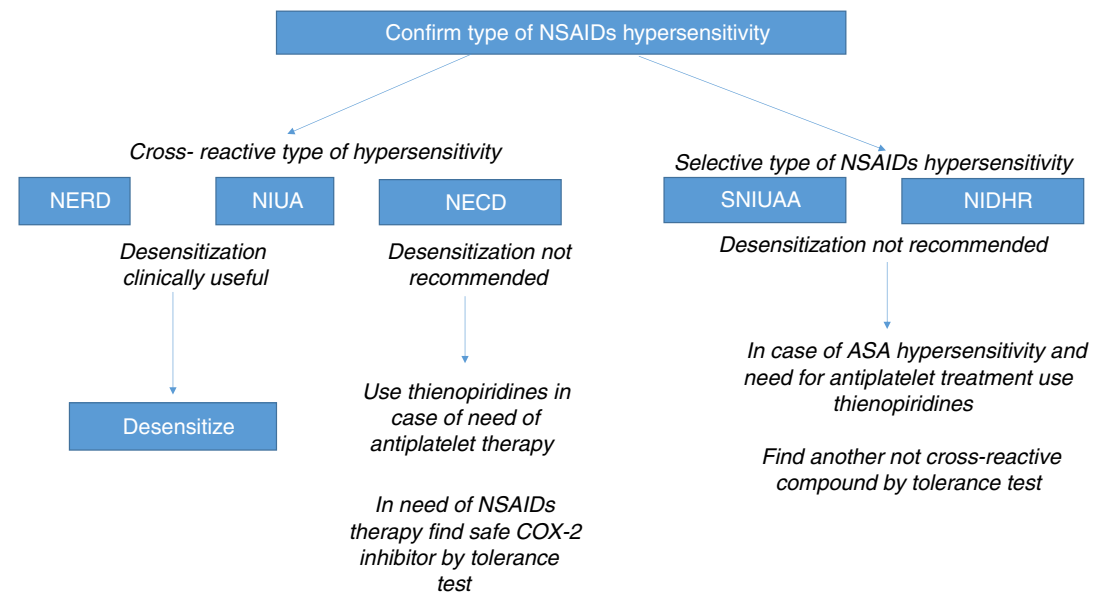

Fig. 1. Steps in management in different subtypes of NSAIDs hypersensitivity. NERD (NSAIDS-exacerbated respiratory disease), NIUA (NSAIDs-induced urticaria/ angioedema), NECD (NSAIDs-exacerbated cutaneous disease), SNIUAA (single NSAIDs-induced urticaria/angioedema/ anaphylaxis), NIDHR (NSAIDs-induced delayed hypersensitivity reaction). 


\section{Conclusions}

defined types of NSAIDs hypersensitivity, diagnosis of hypersensitivity to NSAI Ds was based only on clinical history and usually was not confirmed by challenge test.

There is also a debate about individual aspirin thresholds of aspirin since, as it is known from challenge studies, that some hypersensitive patients may tolerate aspirin in the dose up to $150 \mathrm{mg}$ or even $325 \mathrm{mg}$. In these patients, anti-platelet treatment with low dose of aspirin after standard "desensitization" procedure can be still below the threshold dose that can evoke reaction $[54,66,68]$. These considerations support the recommendations that the first step in management of a patient with hypersensitivity reaction to NSAIDs is to confirm the presence of hypersensitivity by

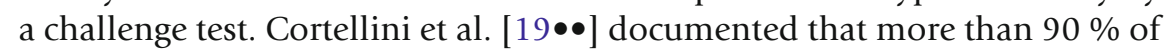
cardiac patients who underwent provocation procedure with increasing doses of aspirin could tolerate up to $1600 \mathrm{mg}$ of the drug. If a rapid introduction of aspirin therapy is needed in a patient with cardiovascular disease and ASA-hypersensitivity, desensitization should be considered as the first choice.

In patients who have contraindications to aspirin desensitization use of alternative treatment is recommended [78] (Fig. 1).

Hypersensitivity to aspirin and other NSAIDs is quite common in the community. Aging population have greater needs to be treated with aspirin or other NSAIDs to prevent cardiovascular events, cancers and to improve control of rhinosinusitis and asthma, thus may be at higher risk for development of hypersensitivity reactions. Due to its exceptional pharmacological properties, aspirin is not easily replaceable in clinic and yet is a cheap drug. For some patients, desensitization to aspirin may be a cost-effective approach, although patients should be carefully selected for this procedure and the risk-benefit ratio of the procedure and chronic treatment with aspirin should be taken into consideration.

\section{Acknowledgments}

The authors are partially supported by the Healthy Ageing Research Centre project (REGPOT-2012-2013-1, 7FP).

\section{Compliance with Ethics Guidelines}

\section{Conflict of Interest}

Joanna Makowska declares that she has no conflicts of interest. Marcin Makowski declares that he has no conflicts of interest. Marek L. Kowalski declares that he has no conflicts of interest.

\section{Human and Animal Rights and Informed Consent}

This article does not contain any studies with human or animal subjects performed by any of the authors. 
Papers of particular interest, published recently, have been highlighted as:

- Of importance

$\bullet \quad$ Of major importance

1. Conaghan PG. A turbulent decade for NSAIDs: update on current concepts of classification, epidemiology, comparative efficacy, and toxicity. Rheumatol Int. 2012;32:1491-502.

2. Kowalski ML, Makowska JS, Blanca M, et al. Hypersensitivity to nonsteroidal anti-inflammatory drugs (NSAIDs) -classification, diagnosis and management: review of the EAACI/ENDA(\#) and GA2LEN/HANN A*. Allergy. 2011;66:818-29.

3. Szczeklik A, Nizankowska E, Duplaga M. Natural history of aspirin-induced asthma. AIANE Investigators European Network on Aspirin-Induced Asthma Eur Respir J. 2000;16:432-6.

4.• Kowalski ML, Asero R, Bavbek S, et al. Classification and practical approach to the diagnosis and management of hypersensitivity to nonsteroidal anti-inflammatory drugs. Allergy. 2013;68:121932.

Position paper of EAACI on NSAIDs hypersensitivity, proposing new nomenclature of NSAIDs hypersensitivity and evidence-based approach to patients with different types of NSAI Ds hypersensitivity.

5.•• Demoly P, Adkinson NF, Brockow K, et al. International Consensus on drug allergy. Allergy. 2014;69:420-37.

International consensus on drug allergy, proposing diagnostic tools and management rules for drug hypersensitivity.

6. Samter M, Beers Jr RF. Intolerance to aspirin. Clinical studies and consideration of its pathogenesis. Ann Intern Med. 1968;68:975-83.

7. Kowalski ML, Cieslak M, Perez-Novo CA, Makowska JS, Bachert C. Clinical and immunological determinants of severe/refractory asthma (SRA): association with Staphylococcal superantigen-specific IgE antibodies. Allergy. 2011;66:32-8.

8. Celik G, Pasaoglu G, Bavbek S, et al. Tolerability of selective cyclooxygenase inhibitor, celecoxib, in patients with analgesic intolerance. J Asthma. 2005;42:127-31.

9. Bavbek S, Celik G, Ozer F, Mungan D, Misirligil Z. Safety of selective COX-2 inhibitors in aspirin/ nonsteroidal anti-inflammatory drug-intolerant patients: comparison of nimesulide, meloxicam, and rofecoxib. J Asthma. 2004;41:67-75.

10. Asero R. Risk factors for acetaminophen and nimesulide intolerance in patients with NSAIDinduced skin disorders. Ann Allergy Asthma Immunol. 1999;82:554-8.

11.• Swierczynska-Krepa M, Sanak M, Bochenek G, Strek P, Cmiel A, Gielicz A, Plutecka H, Szczeklik A, Nizankowska-Mogilnicka E. Aspirin desensitization in patients with aspirin-induced and aspirin-tolerant asthma: A double-blind study. J Allergy Clin Immunol 2014.

Very important placebo-controlled study proving efficacy of aspirin desensitization and aspirin treatment in patients with asthma, nasal polyposis and NSAIDs hypersensitivity.

12. Berges-Gimeno MP, Simon RA, Stevenson DD. Longterm treatment with aspirin desensitization in asthmatic patients with aspirin-exacerbated respiratory disease. J Allergy Clin Immunol. 2003;111:180-6.

13. Mastalerz L, Setkowicz M, Sanak M, Szczeklik A. Hypersensitivity to aspirin: common eicosanoid alterations in urticaria and asthma. J Allergy Clin Immunol. 2004;113:771-5.

14. Dona I, Blanca-Lopez N, Jagemann LR, et al. Response to a selective COX-2 inhibitor in patients with urticaria/ angioedema induced by nonsteroidal antiinflammatory drugs. Allergy. 2011;66:1428-33.

15. Simon RA. Prevention and treatment of reactions to NSAIDs. Clin Rev Allergy Immunol. 2003;24:189-98.

16. Slowik SM, Slavin RG. Aspirin desensitization in a patient with aspirin sensitivity and chronic idiopathic urticaria. Ann Allergy Asthma Immunol.

2009;102:171-2.

17. Grzelewska-Rzymowska I, Roznlecki J, Szmidt M. Aspirin "desensitization" in patients with aspirin-induced urticaria and angioedema. Allergol Immunopathol (Madr). 1988;16:305-8.

18. Dona I, Blanca-Lopez N, Cornejo-Garcia JA, et al. Clin Exp Allergy. 2011;41:86-95.

Study presenting cohort of patients with cross-reactive and single -reactive types of NSAIDs hypersensitivity.

19.• Cortellini G, Testi S, Severino M, et al. Aspirin challenge/desensitisation before coronary stenting in subjects with history of hypersensitivity. A pragmatic approach. Eur Ann Allergy Clin Immunol. 2012;44:1602.

The study proposing approach to patients with need of antiplatelet treatment based on stratification of reaction severity.

20. Wong JT, Nagy CS, Krinzman SJ, Maclean JA, Bloch KJ. Rapid oral challenge-desensitization for patients with aspirin-related urticaria-angioedema. J Allergy Clin Immunol. 2000;105:997-1001.

21. Silberman S, Neukirch-Stoop C, Steg PG. Rapid desensitization procedure for patients with aspirin hypersensitivity undergoing coronary stenting. Am J Cardiol. 2005;95:509-10.

22. Kowalski ML, Bienkiewicz B, Woszczek G, Iwaszkiewicz J, Poniatowska M. Diagnosis of pyrazolone drug sensitivity: clinical history versus skin testing and in vitro testing. Allergy Asthma Proc. 1999;20:347-52. 
23. Pirmohamed M, James S, Meakin S, et al. Adverse drug reactions as cause of admission to hospital: prospective analysis of 18820 patients. BMJ. 2004;329:15-9.

24. Gebhardt M, Wollina U. Cutaneous side-effects of nonsteroidal anti-inflammatory drugs (NSAID). Z Rheumatol. 1995;54:405-12.

25. Patel MR, Marfatia YS. Clinical study of cutaneous drug eruptions in 200 patients. Indian J Dermatol Venereol Leprol. 2008;74:430.

26. Barbaud A. Contact dermatitis due to topical drugs. G Ital Dermatol Venereol. 2009; 144:527-36.

27. Ward KE, Archambault R, Mersfelder TL. Severe adverse skin reactions to nonsteroidal antiinflammatory drugs: a review of the literature. Am J Health Syst Pharm. 2010;67:206-13.

28. Mockenhaupt M, Kelly JP, Kaufman D, Stern RS. The risk of Stevens-Johnson syndrome and toxic epidermal necrolysis associated with nonsteroidal antiinflammatory drugs: a multinational perspective. J Rheumatol. 2003;30:2234-40.

29. Sidoroff A, Dunant A, Viboud C, et al. Risk factors for acute generalized exanthematous pustulosis (AGEP)results of a multinational case-control study (EuroSCAR). Br J Dermatol. 2007;157:989-96.

30. Mihovilovic K, Ljubanovic D, Knotek M. Safe administration of celecoxib to a patient with repeated episodes of nephrotic syndrome induced by NSAIDs. Clin Drug Investig;31:351-5.

31. Ameen KH, Pinninti R, Jami S. Aceclofenac induced Stevens-Johnson/toxic epidermal necrolysis overlap syndrome. J Pharmacol Pharmacother. 2013;4:69-71.

32. Rozieres A, Vocanson M, Said BB, Nosbaum A, Nicolas JF. Role of T cells in nonimmediate allergic drug reactions. Curr Opin Allergy Clin Immunol. 2009;9:30510.

33. Pichler WJ. Delayed drug hypersensitivity reactions. Ann Intern Med. 2003;139:683-93.

34. Cernadas JR, Brockow K, Romano A, et al. General considerations on rapid desensitization for drug hypersensitivity - a consensus statement. Allergy. 2010;65:1357-66.

35. Halvorsen S, Andreotti F, ten Berg JM, et al. Aspirin therapy in primary cardiovascular disease prevention: a position paper of the European Society of Cardiology working group on thrombosis. J Am Coll Cardiol. 2014;64:319-27.

36. Smith Jr SC, Allen J, Blair SN, et al. Aha/Acc, National Heart L, Blood I. AHA/ACC guidelines for secondary prevention for patients with coronary and other atherosclerotic vascular disease: 2006 update: endorsed by the National Heart, Lung, and Blood Institute. Circulation. 2006;113:2363-72.

37. Ferrandez A, Piazuelo E, Castells A. Aspirin and the prevention of colorectal cancer. Best Pract Res Clin Gastroenterol. 2012;26:185-95.

38. Trabert B, Ness RB, Lo-Ciganic WH, et al. Aspirin, nonaspirin nonsteroidal anti-inflammatory drug, and acetaminophen use and risk of invasive epithelial ovarian cancer: a pooled analysis in the Ovarian Cancer
Association Consortium. J Natl Cancer Inst. 2014;106:djt431.

39. Nicholas M, Townsend N, Scarborough P, Rayner M. Cardiovascular disease in Europe 2014: epidemiological update. Eur Heart J. 2014;35:2950-9.

40. Bhatt DL. Can clopidogrel and aspirin lower mortality in patients with acute myocardial infarction? Nat Clin Pract Cardiovasc Med. 2006;3:182-3.

41. Theroux P, Ouimet H, McCans J, et al. Aspirin, heparin, or both to treat acute unstable angina. N Engl J Med. 1988;319:1105-11.

42. Chen ZM, Sandercock P, Pan HC, et al. Indications for early aspirin use in acute ischemic stroke: a combined analysis of 40000 randomized patients from the chinese acute stroke trial and the international stroke trial. On behalf of the CAST and IST collaborative groups. Stroke. 2000;31:1240-9.

43. Yusuf S, Zhao F, Mehta SR, Chrolavicius S, Tognoni G, Fox KK. Clopidogrel in unstable angina to prevent recurrent events trial I. Effects of clopidogrel in addition to aspirin in patients with acute coronary syndromes without ST-segment elevation. N Engl J Med. 2001;345:494-502.

44. Fox KA, Mehta SR, Peters R, et al. Clopidogrel in unstable angina to prevent recurrent ischemic events $\mathrm{T}$. Benefits and risks of the combination of clopidogrel and aspirin in patients undergoing surgical revascularization for non-ST-elevation acute coronary syndrome: the Clopidogrel in Unstable angina to prevent recurrent ischemic events (CURE) trial. Circulation. 2004;110:1202-8.

45. Anderson JL, Adams CD, Antman EM, et al. American College of C, American Heart Association Task Force on Practice G, American College of Emergency P, Society for Cardiovascular A, Interventions, Society of Thoracic S, American Association of C, Pulmonary R, Society for Academic Emergency M. ACC/AHA 2007 guidelines for the management of patients with unstable angina/non-ST-Elevation myocardial infarction: a report of the American College of Cardiology/ American Heart Association Task Force on Practice Guidelines (Writing Committee to Revise the 2002 Guidelines for the Management of Patients With Unstable Angina/Non-ST-Elevation Myocardial Infarction) developed in collaboration with the American College of Emergency Physicians, the Society for Cardiovascular Angiography and Interventions, and the Society of Thoracic Surgeons endorsed by the American Association of Cardiovascular and Pulmonary Rehabilitation and the Society for Academic Emergency Medicine. J Am Coll Cardiol. 2007;50:e1-e157.

46. Hamm CW, Bassand JP, Agewall S, et al. Guidelines ESCCFP. ESC Guidelines for the management of acute coronary syndromes in patients presenting without persistent ST-segment elevation: The Task Force for the management of acute coronary syndromes (ACS) in patients presenting without persistent ST-segment elevation of the European Society of Cardiology (ESC). Eur Heart J. 2011;32:2999-3054. 
47. De Luca G, Verdoia M, Binda G, Schaffer A, Suryapranata $\mathrm{H}$, Marino P. Aspirin desensitization in patients undergoing planned or urgent coronary stent implantation. A single-center experience. Int J Cardiol. 2013;167:561-2.

48. Comert S, Celebioglu E, Yucel T, et al. Aspirin $300 \mathrm{mg} /$ day is effective for treating aspirin-exacerbated respiratory disease. Allergy. 2013;68:1443-51.

49. Berges-Gimeno MP, Simon RA, Stevenson DD. Early effects of aspirin desensitization treatment in asthmatic patients with aspirin-exacerbated respiratory disease. Ann Allergy Asthma Immunol. 2003;90:338-41.

50. Sweet JM, Stevenson DD, Simon RA, Mathison DA. Long-term effects of aspirin desensitization-treatment for aspirin-sensitive rhinosinusitis-asthma. J Allergy Clin Immunol. 1990;85:59-65.

51. Gosepath J, Schafer D, Mann WJ. Aspirin sensitivity: long term follow-up after up to 3 years of adaptive desensitization using a maintenance dose of $100 \mathrm{mg}$ of aspirin a day. Laryngorhinootologie. 2002;81:732-8.

52. Rozsasi A, Polzehl D, Deutschle T, et al. Long-term treatment with aspirin desensitization: a prospective clinical trial comparing 100 and $300 \mathrm{mg}$ aspirin daily. Allergy. 2008;63:1228-34.

53. Kowalski ML, Grzelewska-Rzymowska I, Szmidt M, Rozniecki J. Clinical efficacy of aspirin in "desensitised" aspirin-sensitive asthmatics. Eur J Respir Dis. 1986;69:219-25.

54. Stevenson DD. Diagnosis, prevention and treatment of adverse reactions to aspirin and nonsteroidal antiinflammatory drugs. J Allergy Clin Immunol. 1984;74:617-22.

55. Cho KS, Soudry E, Psaltis AJ, et al. Long-term sinonasal outcomes of aspirin desensitization in aspirin exacerbated respiratory disease. Otolaryngol Head Neck Surg. 2014;151:575-81.

56. Lee JY, Simon RA, Stevenson DD. Selection of aspirin dosages for aspirin desensitization treatment in patients with aspirin-exacerbated respiratory disease. J Allergy Clin Immunol. 2007;119:157-64.

57. Woessner KM, White AA. Evidence-based approach to aspirin desensitization in aspirin-exacerbated respiratory disease. J Allergy Clin Immunol. 2014;133:286-7. e1-9.

58. Hope AP, Woessner KA, Simon RA, Stevenson DD. Rational approach to aspirin dosing during oral challenges and desensitization of patients with aspirinexacerbated respiratory disease. J Allergy Clin Immunol. 2009;123:406-10.

59. Macy E, Bernstein JA, Castells MC, et al. Aspirin challenge and desensitization for aspirin-exacerbated respiratory disease: a practice paper. Ann Allergy Asthma Immunol. 2007;98:172-4.

60. White AA, Stevenson DD, Simon RA. The blocking effect of essential controller medications during aspirin challenges in patients with aspirin-exacerbated respiratory disease. Ann Allergy Asthma Immunol. 2005;95:330-5.
61. Szmidt M, Grzelewska-Rzymowska I, Kowalski ML, Rozniecki J. Tolerance to acetylsalicylic acid (ASA) induced in ASA-sensitive asthmatics does not depend on initial adverse reaction. Allergy. 1987;42:182-5.

62. White AA, Bosso JV, Stevenson DD. The clinical dilemma of "silent desensitization" in aspirinexacerbated respiratory disease. Allergy Asthma Proc. 2013;34:378-82.

63. Stevenson DD, Simon RA. Selection of patients for aspirin desensitization treatment. J Allergy Clin Immunol. 2006;118:801-4.

64. Knight A. Desensitization to aspirin in aspirin-sensitive patients with rhino-sinusitis and asthma: a review. J Otolaryngol. 1989;18:165-7.

65. Dor PJ, Vervloet D, Baldocchi G, Charpin J. Aspirin intolerance and asthmal induction of a tolerance and long-term monitoring. Clin Allergy. 1985;15:37-42.

66. Chiu JT. Improvement in aspirin-sensitive asthmatic subjects after rapid aspirin desensitization and aspirin maintenance (ADAM) treatment. J Allergy Clin Immunol. 1983;71:560-7.

67. Naeije N, Bracamonte M, Michel O, Sergysels R, Duchateau J. Effects of chronic aspirin ingestion in aspirin-intolerant asthmatic patients. Ann Allergy. 1984;53:262-4.

68. Kowalski ML, Grzelewska-Rzymowska I, Rozniecki J, Szmidt M. Aspirin tolerance induced in aspirinsensitive asthmatics. Allergy. 1984;39:171-8.

69. Wallace JL, Syer S, Denou E, et al. Proton pump inhibitors exacerbate NSAID-induced small intestinal injury by inducing dysbiosis. Gastroenterology. 2011;141:1314-22. 22 e1-5.

70. Marlicz W, Loniewski I, Grimes DS, Quigley EM. Nonsteroidal anti-inflammatory drugs, proton pump inhibitors, and gastrointestinal injury: contrasting interactions in the stomach and small intestine. Mayo Clin Proc. 2014;89:1699-709.

71. Scheiman JM. The use of proton pump inhibitors in treating and preventing NSAID-induced mucosal damage. Arthritis Res Ther. 2013;15 Suppl 3:S5.

72. McMullan KL, Wedner HJ. Safety of aspirin desensitization in patients with reported aspirin allergy and cardiovascular disease. Clin Cardiol. 2013;36:25-30.

73. Fajt ML, Petrov AA. Outpatient aspirin desensitization for patients with aspirin hypersensitivity and cardiac disease. Crit Pathw Cardiol. 2011;10:17-21.

74. Alijotas-Reig J, San Miguel-Moncin M, Cistero-Bahima A. Aspirin desensitization in the treatment of antiphospholipid syndrome during pregnancy in ASAsensitive patients. Am J Reprod Immunol. 2006;55:4550.

75. Dalmau G, Gaig P, Gazquez V, Merce J. Rapid desensitization to acetylsalicylic acid in acute coronary syndrome patients with NSAID intolerance. Rev Esp Cardiol. 2009;62:224-5.

76. Rossini R, Angiolillo DJ, Musumeci G, et al. Aspirin desensitization in patients undergoing percutaneous coronary interventions with stent implantation. Am J Cardiol. 2008;101:786-9. 
77. Ortega-Loayza AG, Raza S, Minisi AJ, Topaz O, Heller A, Jovin IS. Aspirin desensitization/challenge in 3 patients with unstable angina. Am J Med Sci.

2010;340:418-20.
78. Pattanaik D, Lieberman P, Das P. Aspirin sensitivity and coronary artery disease: implications for the practicing cardiologist. Future Cardiol. 2012;8:555-62. 